\title{
Urbanisation but not biomass fuel smoke exposure is associated with asthma prevalence in four resource-limited settings
}

\author{
Chelsea Gaviola, ${ }^{1}$ Catherine H Miele, ${ }^{1}$ Robert A Wise, ${ }^{1}$ Robert H Gilman, ${ }^{2}$ \\ Devan Jaganath, ${ }^{1}$ J Jaime Miranda, ${ }^{3,4}$ Antonio Bernabe-Ortiz, ${ }^{3,4}$ Nadia N Hansel, ${ }^{1}$ \\ William Checkley, ${ }^{1,2}$ CRONICAS Cohort Study Group
}

\begin{abstract}
${ }^{1}$ Division of Pulmonary and Critical Care, Department of Medicine, School of Medicine, Johns Hopkins University, Baltimore, Maryland, USA ${ }^{2}$ Program in Global Disease Epidemiology and Control, Department of International Health, Bloomberg School of Public Health, Johns Hopkins University, Baltimore, Maryland, USA

${ }^{3}$ CRONICAS Center of Excellence in Chronic Diseases, Universidad Peruana Cayetano Heredia, Lima, Peru

${ }^{4}$ Department of Medicine, School of Medicine, Universidad Peruana Cayetano Heredia, Lima, Peru
\end{abstract}

\section{Correspondence to Dr William Checkley, Division of Pulmonary and Critical Care, School of Medicine, Johns Hopkins University, 1800 Orleans Ave Suite 9121, Baltimore, MD 21287, USA; wcheckl1@jhmi.edu}

CG and CHM contributed equally.

Received 17 July 2015 Revised 3 October 2015 Accepted 30 October 2015 Published Online First 23 December 2015

\begin{abstract}
Background Urbanisation is an important contributor to the prevalence of asthma worldwide, and the burden of this effect in low-income and middle-income countries undergoing rapid industrialisation appears to be growing. We sought to characterise adult asthma prevalence across four geographically diverse settings in Peru and identify both individual and environmental risk factors associated with adult asthma.

Methods We collected sociodemographics, clinical history and spirometry in adults aged $\geq 35$ years. We defined asthma as meeting one of the three criteria: physician diagnosis, self-report of wheezing attack or use of asthma medications. We used multivariable logistic regression to assess individual and environmental factors associated with adult asthma.
\end{abstract}

Results We analysed data from 2953 participants (mean age 55 years; 49\% male). Overall asthma prevalence was $7.1 \%$, which varied with urbanisation: highest in Lima (14.5\%), followed by urban Puno $(4.0 \%)$, semiurban Tumbes (3.8\%) and rural Puno (1.8\%). In multivariable analysis, being male ( $O R=0.60$, $95 \% \mathrm{Cl} 0.39$ to 0.93 ) and living at high altitude $(\mathrm{OR}=0.26,95 \% \mathrm{Cl} 0.16$ to 0.42 ) were associated with lower odds of having asthma, whereas living in an urban setting $(\mathrm{OR}=4.72,95 \% \mathrm{Cl} 3.15$ to 7.23$)$ and family history of asthma $(\mathrm{OR}=1.83,95 \% \mathrm{Cl} 1.19$ to 2.73) were associated with higher odds. Current daily exposure to biomass fuel smoke $(\mathrm{OR}=1.18,95 \% \mathrm{Cl} 0.70$ to 1.91$)$ and smoking $(\mathrm{OR}=0.99,95 \% \mathrm{Cl} 0.73$ to 1.22$)$ were not associated with asthma.

Conclusions These findings confirm that urbanisation is an environmental risk factor of asthma, questions biomass fuel smoke exposure as an important risk factor and proposes high altitude as possibly protective against the development of asthma.

\section{INTRODUCTION}

Asthma affects 300 million people worldwide, and it is responsible for 15 million disability-adjusted life years lost per year. ${ }^{1}$ Asthma is commonly considered to be a childhood disease. ${ }^{2}$ Specifically, $95 \%$ of all patients with asthma have their first asthma episode before 6 years, and outgrowing asthma is common among children with mild disease. $^{2}{ }^{3}$ However, severe asthma in very early

\section{Key messages}

What is the key question?

- We wanted to characterise the prevalence of adult asthma in four resource-limited settings of Peru and identify the individual and environmental factors associated with adult asthma.

What is the bottom line?

- Our study confirmed that urbanisation is an environmental risk factor of asthma and disputed biomass fuel smoke exposure as an important risk factor.

\section{Why read on?}

- The diversity of settings with varying levels of urbanisation, elevation and biomass fuel use allowed for a comprehensive analysis of risk factors associated with the prevalence of asthma in low-income and middle-income countries.

childhood has been shown to persist into adulthood. $^{3}$

Asthma results from the complex interplay between environmental and genetic factors. ${ }^{4}$ There is evidence that supports the link between urbanisation and asthma. ${ }^{5-7}$ It is not fully understood what factors in urbanisation lead to increased prevalence of asthma, but contributing comorbidities include obesity, ${ }^{8}$ increased allergen exposure, ${ }^{6}$ trafficrelated pollution ${ }^{9}$ and poorer nutritional health. ${ }^{10}$ The first report of differences in asthma in urban and rural environments occurred from Germany in $1965 .^{11}$ Since then, there have been many reports of higher rates of asthma symptoms in urban than rural environments, including Africa and Latin America. ${ }^{5-7} 11$ Our study contributes to this body of evidence by characterising asthma in a novel population: Peruvian adults. We also investigated asthma prevalence across diverse settings with varying levels of altitude and biomass fuel use. The diversity of the settings has allowed us to conduct a comprehensive analysis of risk factors associated with asthma in low-income and middle-income countries (LMICs).

In LMICs, rapid industrialisation had led to the accelerated growth of cities. $66 \%$ of the world's 
population is estimated to live in an urban setting by 2050 , and the majority of urban population growth will occur in LMICs, where the pace of urbanisation is most rapid. ${ }^{12}$ It is expected that with this increased urbanisation, the global burden from asthma will worsen considerably, with prevalence estimated to increase by $50 \%$ every decade. ${ }^{1} 13$

We sought to characterise adult asthma prevalence across four geographically diverse but resource-poor settings, including coastal and highland regions. Our secondary objective was to identify risk factors associated with adult asthma. We hypothesised that urbanisation had a multifactorial effect on adult asthma prevalence, with the highest association seen in Lima, the most urbanised study site.

\section{METHODS}

\section{Study setting}

We conducted a population-based study aimed to determine the prevalence of chronic pulmonary and cardiovascular disease across four disparate regions in Peru. The study has been described in detail elsewhere. ${ }^{14}$ The four sites vary by degrees of urbanisation, altitude and prevalence of daily biomass use (table 1). In Lima, the study site was Pampas de San Juan de Miraflores, a periurban community located $25 \mathrm{~km}$ south of Lima's city centre, with approximately 60000 people in about $4 \mathrm{~km}^{2}$, consisting mostly of Andean immigrants. This area is physically diverse and has experienced significant, but unplanned, sprawl. Tumbes is a semiurban sea-level community in the Northern coast of Peru and comprised a group of communities with about 20000 people spread over $80 \mathrm{~km}^{2}$, where the traditional agricultural landscape has become intermixed with rapidly growing urban sections. Puno is a South-Western city in the Andes, located on the shores of Lake Titicaca at $3825 \mathrm{~m}$ above sea level. Within Puno, we enrolled from two sites: an urban setting located at the city centre and a rural setting comprising inhabitants from surrounding communities.

\section{Study design}

We enrolled adults aged $\geq 35$ years and full-time residents of the study sites. We used a computer-generated programme to select a simple random sample of sex-stratified and age-stratified participants, and approximately 1000 subjects were enrolled per site. In Puno, recruitment was stratified to include 500 participants each from urban and rural settings. ${ }^{14}$ Exclusion criteria were pregnancy, physical disability that prevented the measurement of blood pressure or anthropometry, or active pulmonary TB. All participants provided verbal informed consent. Informed consents were verbal because of high illiteracy rates. The study was approved by the Institutional Review Boards of Universidad Peruana Cayetano Heredia and A.B. PRISMA, in Lima, Peru, and the Johns Hopkins Bloomberg School of Public Health in Baltimore, USA.

\section{Data collection}

Data collection took place over 12 months. Study questionnaires and procedures were conducted at our study centre or alternatively in participants' homes or nearest community centres. Participants responded to a questionnaire on sociodemographics, smoking history, respiratory symptoms, medical history and family history of disease. ${ }^{14}$ Medical history was selfreported. A detailed questionnaire also evaluated the frequency and duration of cooking with biomass fuels. All questionnaires were conducted in a face-to-face interview by trained field workers. Field workers then measured weight and height using standardised techniques. Spirometry was conducted using the Easy-On-PC spirometer (ndd, Zurich, Switzerland) before and after $200 \mathrm{mcg}$ of inhaled salbutamol via a spacer. Trained technicians measured prebronchodilator spirometry and postbronchodilator spirometry in participants following joint American Thoracic Society and European Respiratory Society guidelines. ${ }^{15}$ We adapted a standardised grading system for quality control, review and interpretation. ${ }^{16}$ Participants with low-quality spirometry were asked to repeat the test on another day for a total of three attempts. Overall, 96\% of tests achieved an acceptable result and 95\% met ATS/ERS criteria. We did not perform spirometry on any subject who had surgery of the heart, chest, lungs or eyes in the last 3 months or heart attack in the last 3 months, or blood pressure $>180 \mathrm{~mm} \mathrm{Hg}$ (systolic) or $>100 \mathrm{~mm} \mathrm{Hg}$ (diastolic). We did not use bronchodilators in participants with a heart rate $>120 \mathrm{bpm}$. We rescheduled spirometry at a later date for participants who reported having a respiratory infection in the last 2 weeks, who had used shortterm bronchodilators in the last $4 \mathrm{~h}$ or long-term bronchodilators in the last $12 \mathrm{~h}$ or who had smoked in the last hour.

\section{Definitions}

Adults were defined as having asthma if they met any of the following three criteria: (1) physician-diagnosis of asthma, (2) selfreported wheezing attack in the last 12 months, or (3) use of asthma medications in the last 12 months (table 2). We selected this definition because: (1) there were important differences in lung function between participants with and without asthma (table 2), (2) it minimised the asthma-COPD overlap syndrome (table 2) and (3) the reported prevalence using this definition was consistent with previous literature in our setting. ${ }^{17} \mathrm{We}$ defined COPD as having a postbronchodilator $\mathrm{FEV}_{1} /$ FVC $<0.7{ }^{14}$ We defined reversibility as an improvement of greater than $12 \%$ and $200 \mathrm{~mL}$ in forced expiratory volumes.

We defined high altitude as either living in urban or rural Puno. While there was a gradient of urbanisation across our

Table 1 Description of site characteristics

\begin{tabular}{|c|c|c|c|c|c|c|}
\hline & Urbanisation & Setting & Vehicular traffic & Development & Altitude & $\begin{array}{l}\text { Daily use of } \\
\text { biomass fuels }\end{array}$ \\
\hline Lima & Urban & Dense shanty town outside centre of Lima & Dense throughout the day (50) & Paved and dirt roads & Sea level & Rare \\
\hline $\begin{array}{l}\text { Urban } \\
\text { Puno }\end{array}$ & Urban & Dense city centre & $\begin{array}{l}\text { Dense between } 7: 00 \text { to } 19: 00 \text {, otherwise } \\
\text { minimal }\end{array}$ & Primarily paved roads & $\begin{array}{l}3825 \mathrm{~m} \\
\text { elevation }\end{array}$ & Rare \\
\hline Tumbes & Semiurban & $\begin{array}{l}\text { Semiurban setting with enrolment } \\
\text { predominantly from farming communities } \\
\text { far from city centre }\end{array}$ & $\begin{array}{l}\text { Little to none; bicycles and walking are } \\
\text { the primary forms of transportation }\end{array}$ & Primarily dirt roads & Sea level & $\begin{array}{l}\text { Moderately } \\
\text { prevalent }\end{array}$ \\
\hline $\begin{array}{l}\text { Rural } \\
\text { Puno }\end{array}$ & Rural & Farming communities far from city centre & $\begin{array}{l}\text { Little to none; bicycles and walking are } \\
\text { the primary forms of transportation }\end{array}$ & All dirt roads & $\begin{array}{l}3825 \mathrm{~m} \\
\text { elevation }\end{array}$ & Highly prevalent \\
\hline
\end{tabular}




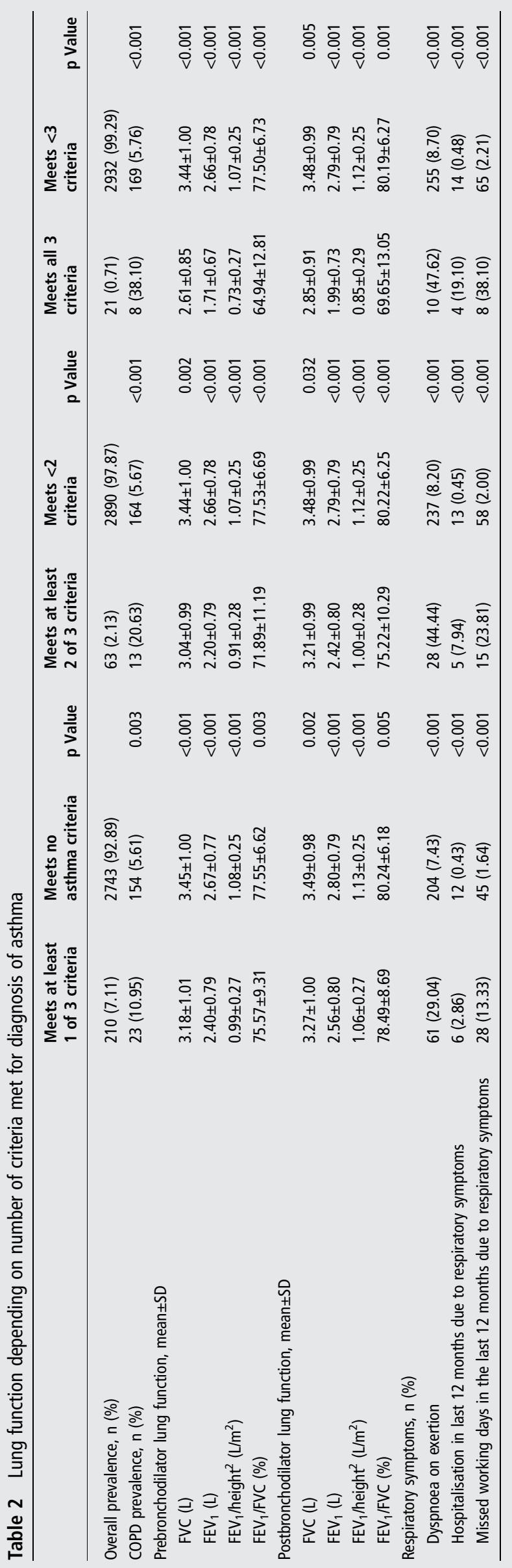

settings (Lima was the most urbanised, followed by urban Puno, semiurban Tumbes and rural Puno), we defined Lima and urban Puno as urban. We created a wealth index according to assets, household facilities, household income and occupation. ${ }^{18} \mathrm{We}$ defined daily smoking as having at least one cigarette a day and hypertension as having systolic blood pressure $\geq 140 \mathrm{~mm} \mathrm{Hg}$ or diastolic blood pressure $\geq 90 \mathrm{~mm} \mathrm{Hg}$, self-report of a physician diagnosis or current use of antihypertensive medications.

\section{Biostatistical analysis}

We used tests or Mann-Whitney tests to compare continuous variables and $\chi^{2}$ or Fisher exact tests to compare categorical variables between groups, as appropriate. We constructed a multivariable logistic regression model of asthma as a function of urbanisation and adjusted for age, sex, height, living at high altitude, smoking, body mass index (BMI), having hypertension, daily use of biomass fuels, family history of asthma and socioeconomic status. Statistical analyses were conducted in R (http:// www.r-project.org).

\section{RESULTS}

\section{Participant characteristics}

We enrolled 4325 participants of whom 3601 (83\%) had complete questionnaires. Of these, 2953 (79\%) had complete spirometry and were considered to have complete data. Non-participation occurred when a participant declined answering specific questions or did not complete components of the study. There were no differences in age $(p=0.21)$, sex $(p=0.97)$, daily smoking $(p=0.51)$, daily biomass use $(p=0.66)$, wealth index $(p=0.44)$, site $(p=0.49)$, or prevalence of asthma $(\mathrm{p}=0.62)$ among participants with or without complete data.

Among the 2953 participants, average age was 55.4 years and $49.3 \%$ were male (table 3 ). There was marked variation by site in reported family history of asthma with a gradient that corresponded to the degree of urbanisation $(p<0.001)$. The prevalence of obesity was higher at the sea-level sites versus high altitude sites $(\mathrm{p}<0.001)$. Daily smoking was low across all sites, with the lowest prevalence in rural Puno and the highest in Tumbes $(\mathrm{p}<0.001) .{ }^{19}$ Median pack-years among smokers was low, at 0.2 pack-years. Daily biomass fuel use was highest in Rural Puno, moderate in Tumbes and minimal in Lima and urban Puno $(\mathrm{p}<0.001)$.

\section{Asthma prevalence and characteristics}

A total of 210 participants $(7.1 \%)$ had asthma. At each of the four sites, asthma diagnosis was most commonly based on meeting one of the two following criteria: Physician diagnosis or wheezing in the last 12 months. Details of criteria met by site can be found in table 3. Participants who met criteria for asthma were more likely to meet spirometry definition for COPD (11.0\%) compared with those without asthma (5.6\%). We found a noticeable variation in asthma prevalence by site with a gradient that corresponded to the degree of urbanisation (table 3). We compared the characteristics of participants with asthma to those without asthma (table 4). Participants with asthma were more likely to be female and had a higher BMI. Those with asthma had worse lung function and were more likely to report dyspnoea on exertion, hospitalisation and missed working days due to respiratory symptoms (table 2). Participants with asthma were also more likely to report family history of asthma (table 4). Notably, those with asthma had a lower prevalence of daily smoking and a lower prevalence of daily biomass fuel usage. 
Table 3 Characteristics of study population by site

\begin{tabular}{|c|c|c|c|c|c|c|}
\hline & Lima & Urban Puno & Tumbes & Rural Puno & Total & p Value \\
\hline Participants & 998 & 503 & 946 & 506 & 2953 & \\
\hline \multicolumn{7}{|l|}{ General characteristics } \\
\hline Age (years), mean $\pm S D$ & $55.0 \pm 11.8$ & $55.3 \pm 12.1$ & $55.8 \pm 13.2$ & $55.5 \pm 12.5$ & $55.4 \pm 12.4$ & 0.573 \\
\hline Male, $\mathrm{n}(\%)$ & $492(49.3)$ & $249(49.5)$ & $475(50.2)$ & $240(47.4)$ & $1456(49.3)$ & 0.794 \\
\hline Weight $(\mathrm{kg})$, mean \pm SD & $68.2 \pm 11.8$ & $68.7 \pm 12.0$ & $71.1 \pm 13.1$ & $61.0 \pm 10.6$ & $68.0 \pm 12.6$ & $<0.001$ \\
\hline BMI $\left(\mathrm{kg} / \mathrm{m}^{2}\right)$, mean $\pm S D$ & $28.4 \pm 4.4$ & $27.9 \pm 4.4$ & $28.3 \pm 4.7$ & $25.2 \pm 3.7$ & $27.8 \pm 4.6$ & $<0.001$ \\
\hline Obese $\left(\mathrm{BMI} \geq 30 \mathrm{~kg} / \mathrm{m}^{2}\right), \mathrm{n}(\%)$ & $329(39.6)$ & $135(16.3)$ & $309(37.2)$ & $57(6.9)$ & $830(27.4)$ & $<0.001$ \\
\hline \multicolumn{7}{|l|}{ Criteria for asthma diagnosis, n (\%) } \\
\hline Physician diagnosis & $82(8.2)$ & $13(2.6)$ & $16(1.7)$ & $3(0.6)$ & $114(3.9)$ & $<0.001$ \\
\hline $\begin{array}{l}\text { Used asthma medications within last } \\
12 \text { months }\end{array}$ & $37(3.7)$ & $6(1.2)$ & $8(0.8)$ & $0(0.0)$ & $51(1.7)$ & $<0.001$ \\
\hline Wheezing attack within the last 12 months & $90(9.0)$ & $9(1.8)$ & $24(2.5)$ & $6(1.2)$ & $129(4.4)$ & $<0.001$ \\
\hline Asthma prevalence, n (\%) & $145(14.5)$ & $20(4.0)$ & $36(3.8)$ & $9(1.8)$ & $210(7.1)$ & $<0.001$ \\
\hline \multicolumn{7}{|l|}{ Wealth index, $\mathrm{n}(\%)$} \\
\hline Low & $119(11.9)$ & $120(23.9)$ & $307(32.5)$ & $356(70.4)$ & $902(30.5)$ & $<0.001$ \\
\hline Middle & $366(36.7)$ & $129(25.6)$ & $387(40.9)$ & $136(26.9)$ & 1018 (34.5) & \\
\hline High & $513(51.4)$ & $254(50.5)$ & $252(26.6)$ & $14(2.8)$ & $1033(35.0)$ & \\
\hline \multicolumn{7}{|l|}{ Self-reported physician diagnoses, n (\%) } \\
\hline History of stroke & $10(1.0)$ & $1(0.2)$ & $2(0.2)$ & $0(0.0)$ & $13(0.4)$ & 0.018 \\
\hline History of TB & $69(6.9)$ & $3(0.6)$ & $7(0.7)$ & $7(1.4)$ & $86(2.9)$ & $<0.001$ \\
\hline History of chronic bronchitis & $69(6.9)$ & $30(6.0)$ & $13(1.4)$ & $3(0.6)$ & $115(3.9)$ & $<0.001$ \\
\hline History of COPD & $2(0.2)$ & $1(0.2)$ & $0(0.0)$ & $1(0.2)$ & $4(0.1)$ & 0.467 \\
\hline History of emphysema & $1(0.1)$ & $0(0.0)$ & $0(0.0)$ & $0(0.0)$ & $1(0.0)$ & 1.000 \\
\hline Family history of asthma, n (\%) & $146(14.6)$ & $18(3.6)$ & $51(5.4)$ & $8(1.6)$ & $223(7.6)$ & $<0.001$ \\
\hline \multicolumn{7}{|l|}{ Exposures } \\
\hline Daily smoking, n (\%) & $32(3.2)$ & $11(2.2)$ & $53(5.6)$ & $1(0.2)$ & $97(3.2)$ & $<0.001$ \\
\hline Prevalence of $\geq 10$ pack-years smoking, $n(\%)$ & $28(2.8)$ & $15(3.0)$ & $50(5.3)$ & $6(1.2)$ & $99(3.4)$ & $<0.001$ \\
\hline Smoking per 10 pack-years, mean \pm SD & $0.13 \pm 0.64$ & $0.09 \pm 0.44$ & $0.22 \pm 0.86$ & $0.03 \pm 0.22$ & $0.13 \pm 0.65$ & $<0.001$ \\
\hline Daily biomass fuel use, n (\%) & $61(6.1)$ & $25(5.0)$ & $221(23.4)$ & $483(95.5)$ & $790(26.8)$ & $<0.001$ \\
\hline
\end{tabular}

\section{Factors associated with asthma}

We performed a single variable analysis and identified several potential demographic, environmental, behavioural and clinical factors (table 5). We considered the major components that made each site unique (tables 1 and 3) and included those components as risk factors for asthma in our analyses. The single variable analysis suggested that sex, height, altitude, BMI, urbanisation, family history of asthma and biomass fuel usage may be associated with asthma prevalence (table 5). We noticed a gradient in asthma prevalence between urban and rural environments both at high altitude $(4.0 \%$ vs $1.8 \% ; \mathrm{p}=0.04)$ and sea-level $(14.5 \%$ vs $3.8 \% ; \mathrm{p}<0.001)$. In multivariable analysis, we found being male and living at a high altitude were both associated with lower odds of having asthma. Conversely, living in an urban setting and having a family history of asthma were associated with a higher odds of having asthma. Notably, BMI and biomass fuel usage were not associated with asthma in multivariable analyses. We repeated this analysis excluding participants with COPD (postbronchodilator $\mathrm{FEV}_{1} / \mathrm{FVC}<0.7$ ) and found that the results were unchanged: male sex $(\mathrm{OR}=0.61 ; \mathrm{p}=0.04)$ and high altitude $(\mathrm{OR}=0.24 ; \mathrm{p}<0.001)$ were associated with a decreased odds of having asthma and urban living $(\mathrm{OR}=4.33$; $\mathrm{p}<0.001)$ and family history of asthma $(\mathrm{OR}=1.88 ; \mathrm{p}=0.004)$ were associated with increased odds of having asthma. Biomass fuel exposure remained non-significant $(\mathrm{OR}=1.08 ; \mathrm{p}=0.79)$.

\section{DISCUSSION}

In this multicentre, population-based study in Peru, we found significant variation in asthma prevalence across four resource- poor sites with varying degrees of urbanisation, altitude and biomass fuel usage. We observed a clear gradient that corresponded to the degree of urbanisation for both asthma prevalence and family history of asthma prevalence, suggesting that urbanisation increases asthma prevalence. Asthma was associated with being female, living at low altitude, having a family history of asthma and living in an urban setting. We did not find any association between daily biomass fuel and asthma.

We found that the asthma prevalence was 7.1\% among adults across four sites in Peru. A study in Cameroon characterised adulthood asthma and determined that the overall prevalence was $2.7 \%$, based on self-reported diagnosis of asthma by a health professional. ${ }^{20}$ This value was similar to our findings of self-reported physician diagnosis of asthma (3.9\%). ${ }^{20}$ According to a study by To et al, ${ }^{17}$ who analysed World Health Survey data collected between 2002 and 2003, the estimated prevalence of asthma in Latin America among adults was $4.3 \%$ for doctordiagnosed asthma, 4.4\% for clinical asthma and 7.6\% for wheezing symptoms. Our estimates of asthma prevalence are in line with the estimates of To et al. ${ }^{17}$ Ultimately, by using a more comprehensive definition of asthma, as we chose to do for our study, we increased sensitivity for detecting asthma prevalence, which is important in LMICs where not everyone has access to a physician for accurate diagnosis. ${ }^{17}$

In the literature, urbanisation is recognised as a risk factor for asthma, and the gradient we observed by site and the association found in our multivariable analysis results confirmed the negative impact between urbanisation and asthma prevalence. ${ }^{5-7}$ It is still not well understood what factors in urbanisation contribute 
Table 4 Characteristics of asthma and non-asthma subjects

\begin{tabular}{|c|c|c|c|}
\hline & Asthma & No Asthma & p Value \\
\hline Overall prevalence, $\mathrm{n}(\%)$ & $210(7.1)$ & $2743(92.9)$ & \\
\hline \multicolumn{4}{|l|}{ Demographic characteristics } \\
\hline \multicolumn{4}{|l|}{ Gender, n (\%) } \\
\hline Male & $81(38.6)$ & $1375(50.1)$ & 0.002 \\
\hline Female & $129(61.4)$ & $1368(49.9)$ & \\
\hline Age (years), mean $\pm S D$ & $55.7 \pm 12.3$ & $55.4 \pm 12.4$ & 0.713 \\
\hline \multicolumn{4}{|l|}{ Clinical measurements, mean \pm SD } \\
\hline Height $(\mathrm{cm})$ & $154.4 \pm 8.6$ & $156.6 \pm 8.7$ & $<0.001$ \\
\hline Weight (kg) & $68.5 \pm 11.5$ & $67.9 \pm 12.6$ & 0.51 \\
\hline $\mathrm{BMI}\left(\mathrm{kg} / \mathrm{m}^{2}\right)$ & $28.8 \pm 4.6$ & $27.7 \pm 4.6$ & $<0.001$ \\
\hline \multicolumn{4}{|l|}{ BMI categories, $\mathrm{n}(\%)$} \\
\hline Low & $1(0.4)$ & $6(0.2)$ & 0.404 \\
\hline Normal & $41(19.5)$ & $774(28.2)$ & 0.008 \\
\hline Overweight & $92(43.8)$ & $1209(44.1)$ & 0.998 \\
\hline Obese & $76(36.2)$ & $754(27.5)$ & 0.009 \\
\hline Systolic blood pressure $(\mathrm{mm} \mathrm{Hg})$ & $116.9 \pm 19.8$ & $117.3 \pm 18.7$ & 0.788 \\
\hline Hypertension, n (\%) & $52(24.8)$ & $535(19.5)$ & 0.080 \\
\hline \multicolumn{4}{|l|}{ Respiratory indicators, mean $\pm S D$} \\
\hline Pre-FVC (L) & $3.18 \pm 1.01$ & $3.45 \pm 1.00$ & $<0.001$ \\
\hline Pre-FEV 1 (L) & $2.40 \pm 0.79$ & $2.67 \pm 0.77$ & $<0.001$ \\
\hline Preratio (\%) & $75.57 \pm 9.31$ & $77.55 \pm 6.62$ & 0.003 \\
\hline Post-FVC (L) & $3.27 \pm 1.00$ & $3.49 \pm 0.98$ & 0.002 \\
\hline Post-FEV ${ }_{1}$. (L) & $2.56 \pm 0.80$ & $2.80 \pm 0.79$ & $<0.001$ \\
\hline Postratio (\%) & $78.49 \pm 8.69$ & $80.24 \pm 6.18$ & 0.005 \\
\hline $\begin{array}{l}\text { Height adjusted (pre-FEV } 1 / \text { height }^{2} \text { ) } \\
\left(\mathrm{L} / \mathrm{m}^{2}\right)\end{array}$ & $0.99 \pm 0.27$ & $1.08 \pm 0.25$ & $<0.001$ \\
\hline $\begin{array}{l}\left.\text { Height adjusted (post-FEV } 1 / \text { height }^{2}\right) \\
\left(\mathrm{L} / \mathrm{m}^{2}\right)\end{array}$ & $1.06 \pm 0.27$ & $1.13 \pm 0.25$ & $<0.001$ \\
\hline Reversibility, n (\%) & $35(16.7)$ & $297(10.8)$ & 0.014 \\
\hline \multicolumn{4}{|l|}{ Self-reported physician diagnoses, $\mathrm{n}(\%)$} \\
\hline History of hypertension & $70(33.3)$ & $462(15.7)$ & $<0.001$ \\
\hline History of heart disease & $17(8.1)$ & $99(3.4)$ & 0.002 \\
\hline History of stroke & $1(0.5)$ & $12(0.4)$ & 0.618 \\
\hline History of TB & $15(7.1)$ & $71(2.6)$ & $<0.001$ \\
\hline History of chronic bronchitis & $42(20.0)$ & $73(2.7)$ & $<0.001$ \\
\hline History of COPD & $1(0.5)$ & $3(0.1)$ & 0.256 \\
\hline History of emphysema & $0(0.00)$ & $1(0.04)$ & 1.000 \\
\hline Family history of asthma, $\mathrm{n}(\%)$ & $35(16.7)$ & $188(6.9)$ & $<0.001$ \\
\hline \multicolumn{4}{|l|}{ Wealth index, $\mathrm{n}(\%)$} \\
\hline Low & $54(25.7)$ & $848(30.9)$ & 0.187 \\
\hline Middle & $72(34.3)$ & $946(34.5)$ & \\
\hline High & $84(40.0)$ & $949(34.6)$ & \\
\hline \multicolumn{4}{|l|}{ Exposures } \\
\hline Daily smoking, n (\%) & $2(1.0)$ & $95(3.5)$ & 0.044 \\
\hline $\begin{array}{l}\text { Prevalence of } \geq 10 \text { pack-years' } \\
\text { smoking, } n(\%)\end{array}$ & $3(1.4)$ & $96(3.5)$ & 0.158 \\
\hline $\begin{array}{l}\text { Smoking per } 10 \text { pack-years, } \\
\text { mean } \pm \text { SD }\end{array}$ & $0.11 \pm 0.82$ & $0.14 \pm 0.64$ & 0.690 \\
\hline Daily biomass fuel usage, $\mathrm{n}(\%)$ & $30(14.3)$ & $760(27.7)$ & $<0.001$ \\
\hline
\end{tabular}

to the increased prevalence of asthma but contributing comorbidities include obesity, ${ }^{8}$ increased antigen exposure with decreased sensitivity, ${ }^{6}$ traffic related pollution ${ }^{9}$ and overall poorer nutritional health. ${ }^{10}$ We also found that family history of asthma was associated with asthma prevalence. This finding aligns well with the literature, where it is well established that hereditary factors contribute to the pathogenesis of asthma. ${ }^{21}$ Obesity and cardiovascular diseases have been linked to urbanisation $^{22}$ and obesity has been associated with asthma. ${ }^{8}$ We found statistically significant differences in BMI, obesity and history of self-reported physician diagnosis of hypertension and heart disease between participants with and without asthma. However, BMI and hypertension were not significantly associated with asthma in the multivariable analysis. This may be due to the strength of the influence of other risk factors and warrants further attention to the topic.

We observed a strong association between high altitude and decreased asthma prevalence. There is limited and conflicting literature on the role of living at high altitude on the risk of asthma. The ISAAC study found no association between altitude and asthma prevalence, ${ }^{23}$ while another study in Mexico found that higher altitude was associated with a lower asthma prevalence. ${ }^{24}$ There could be several explanations for why there is a lower asthma prevalence at high altitudes. One hypothesis is that high altitude environments have a lower presence of allergenic exposures ${ }^{25}$ including pollen and mites, ${ }^{26} 27$ or may have true differences in airway inflammation ${ }^{28}$ or airway responsiveness. ${ }^{29}$ It is also possible that natural selection may play a role. ${ }^{30}$ Well-designed longitudinal studies are needed to further clarify the relationship between asthma and high altitude.

There is more controversy regarding the role of biomass as a risk factor for asthma. ${ }^{31} \mathrm{~A}$ literature search by Diette et $a l^{31}$ found that studies examining biomass and asthma in adults are not uniformly positive and the associations with specific fuel type are inconsistent. The ISAAC study found a strong association between the use of biomass fuels for cooking and asthma in children ${ }^{32}$ and studies in other LMICs have suggested a relationship between biomass fuel exposure and asthma. ${ }^{31} 33$ However, similar to other studies, ${ }^{34} 35$ our multivariable analysis indicates there is no association between daily biomass fuel smoke exposure and asthma prevalence in adults aged 35 years and older. ${ }^{31}$ Given the cross-sectional nature of this study, it is difficult to draw a conclusion; however, this relationship may suggest that biomass fuel exposure is not a risk factor for asthma or could merely reflect the idea that people with asthma avoid biomass fuel smoke because of their symptoms. Further longitudinal studies are needed to address this controversy.

Our study has several strengths. The sample size of the study was robust, with approximately 3000 participants total with 1000 participants per study site. Each site had diverse geographical and social characteristics. Our data collection was comprehensive, including demographic, behavioural, environmental and clinical data. An asthma characterisation study of this scale has not previously been conducted in Peru. Some limitations to this study include inherent biases of cross-sectional studies including under-reporting of self-reported symptoms. Given that our study relies on participant report of symptoms and physician diagnosis, our results are prone to reporting bias, and it is possible that more accessible settings (Lima and urban Puno) would report more clinical findings compared with rural settings (Tumbes and rural Puno). This could mean that the variation in asthma prevalence seen across sites may be exaggerated as two of the asthma diagnostic criteria required a physician evaluation (physician diagnosis and asthma medication usage). We are also missing data on atopy or allergic disease and inflammation, which would have enabled a more thorough analysis of the risk factors.

\section{CONCLUSION}

Previous studies have focused on characterising asthma in children. This study characterised adult asthma prevalence across diverse settings in a low-income and middle-income country, and associated urbanisation, female sex, low altitude and family 
Table 5 Factors associated with greater asthma prevalence across four sites in Peru

\begin{tabular}{|c|c|c|c|c|c|c|}
\hline \multirow[b]{2}{*}{$\mathrm{n}=2953$} & \multicolumn{3}{|c|}{ Single variable } & \multicolumn{3}{|c|}{ Multivariable } \\
\hline & $\mathrm{OR}$ & $95 \% \mathrm{Cl}$ & $\mathrm{p}$ Value & OR & $95 \% \mathrm{Cl}$ & p Value \\
\hline Age (per 10 years) & 1.02 & (0.91 to 1.14 ) & 0.71 & 1.03 & (0.90 to 1.18 ) & 0.68 \\
\hline Male vs female sex (female as reference) & 0.62 & (0.47 to 0.83 ) & 0.001 & 0.60 & (0.39 to 0.93 ) & 0.02 \\
\hline Height $(\mathrm{cm})$ & 0.97 & (0.96 to 0.99$)$ & $<0.001$ & 1.01 & (0.98 to 1.03$)$ & 0.582 \\
\hline High altitude vs sea-level (sea-level as reference) & 0.29 & (0.19 to 0.42$)$ & $<0.001$ & 0.26 & (0.16 to 0.42$)$ & $<0.001$ \\
\hline Smoking per 10 pack-years & 0.94 & (0.68 to 1.16$)$ & 0.62 & 0.99 & (0.73 to 1.22$)$ & 0.93 \\
\hline BMI $\left(\mathrm{kg} / \mathrm{m}^{2}\right)$ & 1.05 & (1.02 to 1.08$)$ & $<0.001$ & 1.02 & (0.98 to 1.05$)$ & 0.35 \\
\hline Urban vs rural (rural as reference) & 3.86 & (2.78 to 5.47 ) & $<0.001$ & 4.72 & (3.15 to 7.23 ) & $<0.001$ \\
\hline Family history of asthma & 2.72 & (1.81 to 3.98$)$ & $<0.001$ & 1.83 & (1.19 to 2.73 ) & 0.004 \\
\hline Hypertension & 1.36 & (0.97 to 1.87 ) & 0.07 & 1.24 & (0.85 to 1.79$)$ & 0.27 \\
\hline Daily vs other biomass fuel usage & 0.43 & (0.29 to 0.63 ) & $<0.001$ & 1.18 & (0.70 to 1.91$)$ & 0.51 \\
\hline High wealth index & 1.26 & (0.94 to 1.68$)$ & 0.11 & 0.80 & (0.54 to 4.02$)$ & 0.16 \\
\hline
\end{tabular}

BMI, body mass index.

history of asthma with asthma in Peruvian adults. We observed a clear gradient that corresponded to the degree of urbanisation for both asthma prevalence and family history of asthma prevalence. We found a limited association between biomass fuel use and asthma prevalence, even when adjusting for altitude. We found that using one of three asthma criteria for the diagnosis of asthma to be sufficient, especially in a low-income and middle-income setting where there is minimal accessibility to a physician for formal diagnosis and treatment. Overall, our results can guide future investigations on adult asthma and provide methods for diagnosing asthma in epidemiological studies in low-income and middle-income countries.

Acknowledgements The authors are indebted to all participants who kindly agreed to participate in the study. Special thanks to all field teams for their commitment and hard work, especially to Lilia Cabrera, Rosa Salirrosas, Viterbo Aybar, Sergio Mimbela and David Danz for their leadership in each of the study sites, as well as Marco Varela for data coordination.

Collaborators CRONICAS Cohort Study Group. Cardiovascular Disease: Juan P Casas, George Davey Smith, Shah Ebrahim, Héctor H García, Luis Huicho, Germán Málaga, Víctor M Montori, Liam Smeeth; Chronic Pulmonary Disease: Gregory B Diette, Luis Huicho, Fabiola León-Velarde, María Rivera; Training and Capacity Building: Héctor H García, Katherine Sacksteder.

Contributors $W C, J J M$, and $A B-O$ conceived, designed and supervised the overall study. WC, JJM, and AB-O coordinated and supervised fieldwork activities in Lima, Tumbes and Puno. CG, CHM, and WC developed the idea for this manuscript, led the statistical analysis, and wrote the first draft. RAW, RHG, DJ, JJM, AB-O, and $\mathrm{NNH}$ participated in writing of the manuscript, provided important intellectual content and gave their final approval of the version submitted for publication. WC had ultimate oversight over study conduct, analysis plan and writing of manuscript.

Funding This project was funded in whole with Federal funds from the US National Heart, Lung, and Blood Institute, National Institutes of Health, Department of Health and Human Services, under Contract No. HHSN268200900033C. CHM was further supported by National Institute of Health Fogarty International Center

(5R25TW009340). WC was further supported by a Pathway to Independence Award (ROOHL096955) from the National Heart, Lung and Blood Institute.

Competing interests None declared.

Patient consent Obtained.

Ethics approval Johns Hopkins University, AB PRISMA, Universidad Peruana Cayetano Heredia.

Provenance and peer review Not commissioned; externally peer reviewed.

\section{REFERENCES}

1 Masoli M, Fabian D, Holt S, et al. The global burden of asthma: executive summary of the GINA Dissemination Committee Report. Allergy 2004;59:469-78.

2 De Nijs SB, Venekamp LN, Bel EH. Adult-onset asthma: is it really different? Eur Respir Rev 2013;22:44-52.
3 Zeki AA, Kenyon NJ, Yoneda K, et al. The adult asthmatic. Clin Rev Allergy Immunol 2012;43:138-55.

4 Eder W, Ege MJ, von Mutius E. The asthma epidemic. N Eng/ J Med 2006;355:2226-35.

5 Rodriguez A, Vaca M, Oviedo $G$, et al. Urbanisation is associated with prevalence of childhood asthma in diverse, small rural communities in Ecuador. Thorax 2011;66:1043-50.

6 Robinson CL, Baumann LM, Romero K, et al. Effect of urbanization on asthma, allergy, and airways inflammation in a developing country setting. Thorax 2011;66:1051-7.

7 Weinberg E. Urbanization and childhood asthma: an African perspective. J Allergy Clin Immunol 2000;105:224-31.

8 Kim S-H, Sutherland ER, Gelfand EW. Is there a link between obesity and asthma? Allergy Asthma Immunol Res 2014;6:189-95.

9 Baumann LM, Robinson CL, Combe JM, et al. Effects of distance from a heavily transited avenue on asthma and atopy in a periurban shantytown in Lima, Peru. J Allergy Clin Immunol 2011;127:875-82.

10 Devereux G. Session 1: allergic disease: nutrition as a potential determinant of asthma. Proc Nutr Soc 2010;69:1-10.

11 Asher M. Urbanisation, asthma and allergies. Thorax 2011;66:1025-2026.

12 United Nations, Department of Economic and Social Affairs, Population Division. World urbanization prospects: The 2014 Revision, Highlights (ST/ESA/SER.A/352). 2014. (cited 16 Jul 2015). http://esa.un.org/unpd/wup/

13 Braman S. The global burden of asthma. Chest J 2006;130:4S-12S.

14 Miranda JJ, Bernabe-Ortiz A, Smeeth L, et al. Addressing geographical variation in the progression of non-communicable diseases in Peru: the CRONICAS cohort study protocol. BMJ Open 2012;2:e000610.

15 Miller M, Hankinson J, Brusasco V, et al. Standardisation of spirometry. Eur Respir J 2005;26:319-38.

16 Ferguson $G$, Enright $P$, Buist $A$, et al. Office spirometry for lung health assessment in adults: a consensus statement from the National Lung Health Education Program. Chest 2000;117:1146-61.

17 To T, Stanojevic S, Moores G, et al. Global asthma prevalence in adults: findings from the cross-sectional world health survey. BMC Public Health 2012;12:204.

18 Howe L, Galobardes B, Matijasevich A, et al. Measuring socio-economic position for epidemiological studies in low- and middle-income countries: a methods of measurement in epidemiology paper. Int J Epidemiol 2012;41:871-86.

19 Weygandt PL, Vidal-Cardenas E, Gilman RH, et al. Epidemiology of tobacco use and dependence in adults in a poor peri-urban community in Lima, Peru. BMC Pulm Med 2012;12:9.

20 Pefura-Yone E, Kengne A, Balkissou A, et al. Prevalence of asthma and allergic rhinitis among adults in Yaounde, Cameroon. PLOS ONE 2015;10:e0123099.

21 Ober C, Yao T-C. The genetics of asthma and allergic disease: a 21 st century perspective. Immunol Rev 2011;242:10-30.

22 Allender S, Foster C, Hutchinson L, et al. Quantification of urbanization in relation to chronic diseases in developing countries: a systematic review. J Urban Health 2008;85:938-51.

23 Chong Neto HJ, Rosario NA, Sole D, et al. Asthma and rhinitis in South America: how different they are from other parts of the world. Allergy Asthma Immunol Res 2012;4:62-7.

24 Vargas MH, Sienra-Monge JJ, Diaz-Mejia G, et al. Asthma and geographical altitude: an inverse relationship in Mexico. J Asthma 1999;36:511-17.

25 Rijssenbeek-Nouwens L, Fleten K, Bron A, et al. High-altitude treatment in atopic and nonatopic patients with severe asthma. Eur Respir J 2012;40:1374-80. 
26 Charpin D, Kleisbauer JP, Lanteaume A, et al. Asthma and allergy to house-dust mites in populations living in high altitudes. Chest 1988;93:758-61.

27 Charpin D, Birnbaum J, Haddi E, et al. Altitude and allergy to house-dust mites. A paradigm of the influence of environmental exposure on allergic sensitization. Am Rev Respir Dis 1991;143:983-6.

28 Cogo A, Basnyat B, Legnani D, et al. Bronchial asthma and airway hyperresponsiveness at high altitude. Respiration 1997;64:444-9.

29 Karagiannidis C, Hense G, Rueckert B, et al. High-altitude climate therapy reduces local airway inflammation and modulates lymphocyte activation. Scand I Immunol 2006;63:304-10.

30 Laniado-Laborin R, Rendón A, Batiz F, et al. High altitude and chronic obstructive pulmonary disease prevalence: a casual or causal correlation? Arch Bronconeumol 2012;48:156-60.
31 Diette GB, Accinelli RA, Balmes JR, et al. Obstructive lung disease and exposure to burning biomass fuel in the indoor environment. Glob Heart 2012;7:265-70.

32 Wong GW, Brunekreef B, Ellwood P, et al. Cooking fuels and prevalence of asthma: a global analysis of phase three of the International Study of Asthma and Allergies in Childhood (ISAAC). Lancet Respir Med 2013;1:386-94.

33 Gonzalez-Garcia M, Caballero A, Jaramillo C, et al. Prevalence, risk factors and underdiagnosis of asthma and wheezing in adults 40 years and older: a population-based study. J Asthma 2015;52:823-30.

34 Thacher J, Emmelin A, Madaki A, et al. Biomass fuel use and the risk of asthma in Nigerian children. Respir Med 2013;107:1845-51.

35 Po JYT, FitzGerald JM, Carlsten C. Respiratory disease associated with solid biomass fuel exposure in rural women and children: systematic review and meta-analysis. Thorax 2011;66:232-9. 